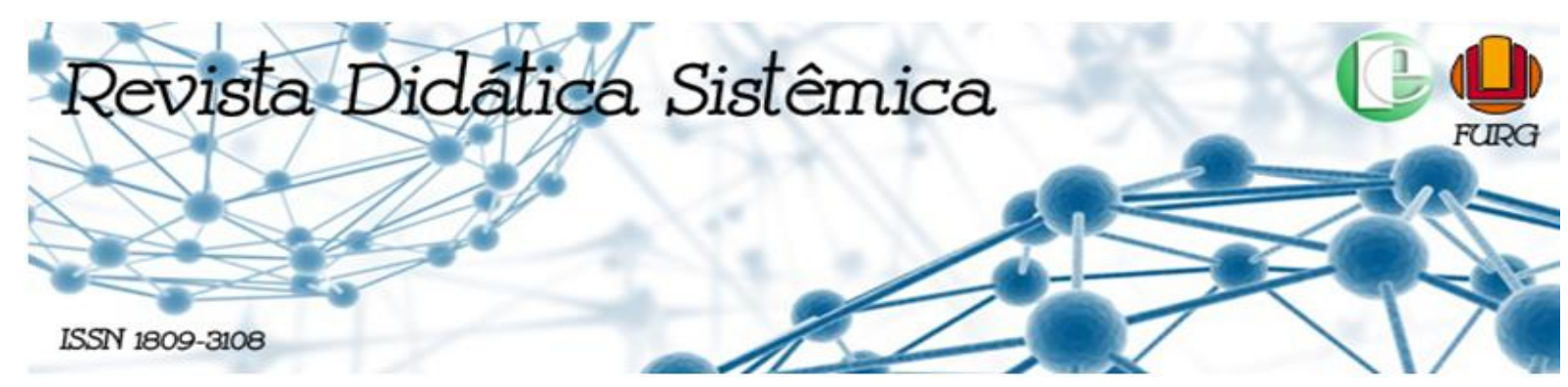

\title{
GESTÃO DEMOCRÁTICA E PARTICIPATIVA: HORIZONTES E POSSIBILIDADES DE CONSTRUIR UMA ESCOLA DE TODOS E PARA TODOS
}

\author{
Fernanda Jardim Vieira* \\ Edna Maria Assêncio Will****** \\ Lamartine Christian de Lima ${ }^{* * *}$
}

\begin{abstract}
RESUMO
A gestão democrática e participativa foi o objeto de análise deste trabalho, no qual visamos estudar os processos democráticos que norteiam e regem a gestão de escolas públicas no Brasil. Considerando o princípio da gestão democrática instituído na legislação vigente como ponto de partida de nosso estudo, fundamentamos este trabalho nas ideias de diferentes estudiosos da área que entendem a gestão democrática como algo imprescindível para a melhoria no ensino público. Analisando o conceito e os fundamentos da gestão escolar democrática, procuramos, por meio deste artigo, construir entendimentos e saberes que auxiliem a comunidade escolar a enfrentar as barreiras que entravam a implantação e efetivação da democratização nos espaços escolares, e abordam os principais fundamentos legais para a implantação da gestão escolar democrática nas escolas. Mesmo a gestão democrática e participativa estando em fase de implantação, pudemos evidenciar, a partir desse estudo, que esse modelo de gestão não só abre espaço para a iniciativa, como também cobra isso da equipe escolar, alunos e pais. A gestão democrática e participativa tem como cerne envolver toda a equipe escolar e a comunidade na construção de uma proposta coletiva com projetos e ações a serem desenvolvidos, visando à melhoria da qualidade do processo de ensino-aprendizagem. Ele envolve a comunidade, abre espaço para novas ideias e incentiva o educando a se tornar um ser crítico e pensante.
\end{abstract}

Palavras-chave: Escola; Gestão Democrática; Gestão Participativa.

\footnotetext{
* Aluna do Programa de Mestrado Profissional em Ensino de História (PROFHISTORIA) da Universidade do Estado de Mato Grosso (UNEMAT). Licenciada em História (Centro Universitário Claretiano - CEUCLAR). Especialista em gestão, orientação educacional e supervisão escolar. Especialista em Metodologia e didática do ensino superior (Faculdades Integradas de Várzea Grande - FIAVEC). Professora da Rede Estadual de Educação de Mato Grosso (SEDUC/MT).

*** Licenciada em Letras/Habilitação em Língua Inglesa (Faculdade de Educação de Colorado do Oeste FAEC). Especialista em Linguística aplicada em Língua Portuguesa. Especialista em Atendimento Educacional Especializado - AEE. Especialista em gestão, orientação educacional e supervisão escolar. Especialista em Psicopedagogia Clínica e Institucional (Faculdades Integradas de Várzea Grande - FIAVEC). Professora da Rede Municipal de Educação de Vilhena/RO - SEMED

**** Licenciado em Ciências (FABEJA - Belo Jardim/PE). Especialista em gestão, orientação educacional e supervisão escolar (Faculdades Integradas de Várzea Grande - FIAVEC). Professor da Rede Municipal de Educação de Vilhena/RO (SEMED).
} 


\title{
DEMOCRATIC AND PARTICIPATORY MANAGEMENT: HORIZONS AND POSSIBILITIES TO BUILD A SCHOOL OF ALL AND FOR ALL.
}

\begin{abstract}
The democratic and participatory management was the object of analysis of this article, in which we aim to study the democratic processes that guide and govern the management of public schools in Brazil. Considering the principle of democratic management instituted in the current legislation as the starting point of our study, we substantiate this article in the ideas of different scholars in the area who understand democratic management as something indispensable for the improvement in public education. Analyzing the concept and fundamentals of democratic school management, we seek through this article to construct understandings and knowledge that help the school community to confront the barriers that hinder the implementation and effectiveness of democratisation in school spaces, in addition to addressing the main legal foundations for the implementation of democratic school management in schools. Even the democratic and participatory management being in the implementation phase, we could evidence from this study that this model of managing It not only opens up space for the initiative, as it charges the school staff, students and parents. The core of the democratic and participatory management is to involve the entire school team and the community in the construction of a collective proposal with projects and actions to be developed, aiming at improving the quality of the teaching learning process. It involves the community, opens up space for new ideas and encourages the learner to become a critical and thinking being.
\end{abstract}

Keywords: School Democratic Management; Participatory Management.

\section{GESTIÓN DEMOCRÁTICA Y PARTICIPATIVA: HORIZONTES Y POSIBILIDADES PARA CONSTRUIR UNA ESCUELA DE TODOS Y PARA TODOS.}

\section{RESUMEN}

La gestión democrática y participativa fue objeto de análisis de esta obra, en la que pretendemos estudiar los procesos democráticos que guían y rigen la gestión de las escuelas públicas en Brasil. Considerando el princípio de la gestión democrática instituido en la legislación actual como el punto de partida de nuestro estudio, corroboramos este trabajo en las ideas de los diversos eruditos en el área que entienden la gerencia democrática como algo indispensable para el Mejoramiento de la educación pública. Analizando el concepto y los fundamentos de la gestión democrática de la escuela, buscamos a través de este artículo construir entendimientos y conocimientos que ayuden a la comunidad escolar a enfrentar las barreras que obstaculizan la implementación y efectividad de la democratización en Espacios escolares, además de abordar los principales fundamentos jurídicos para la implementación de la gestión escolar democrática en las escuelas. Incluso la gestión democrática y participativa que está en la fase de implementación, podríamos evidenciar en este estudio que este modelo de gestión no sólo abre espacio para la iniciativa, ya que cobra al equipo escolar, a los estudiantes y a los padres. El núcleo de la gestión democrática y participativa es involucrar a todo el equipo escolar y a la comunidad en la construcción de una propuesta colectiva con proyectos y acciones a desarrollar, con el objetivo de mejorar la calidad del proceso enseñanza-aprendizaje docente. Involucra a la comunidad, abre espacio para nuevas ideas y anima al alumno a convertirse en un ser crítico y pensante.

Palabras clave: Escuela, Gestión Democrática; Gestión Participativa.

\section{INTRODUÇÃO}

Atualmente, muito se tem discutido sobre a temática da gestão escolar, principalmente das escolas públicas, que, muitas vezes, interioriza uma gestão pautada no conservadorismo e tradicionalismo. Buscamos, com este trabalho, alternativas que viabilizem a efetiva gestão 
democrática dentro do âmbito escolar, tentando, dessa forma, implementar novas posturas na relação entre o gestor e os membros da unidade social.

Como é uma organização social, a escola requer que cada sujeito envolvido em seus processos tenha seu papel definido e participação efetiva para o desenvolvimento das propostas a serem executadas.

É consenso entre os educadores que o funcionamento das escolas públicas depende das ações empreendidas pelos governantes, seja federal, estadual ou municipal. Mas é no âmbito de cada unidade escolar que as diretrizes podem beneficiar ou não a clientela, dependendo, efetivamente, de seu comando ou administração e da maneira com que é aplicada. O gestor é a peça principal para que se execute na escola uma política que promova a democratização e a participação, atendendo às necessidades e anseios dos que compõem a comunidade escolar.

Somente uma escola bem organizada e bem gerida assegura condições pedagógicas, didáticas, organizacionais e operacionais que dão condições ao ensino, de modo que os educandos tenham qualidade na aprendizagem escolar, e isso não depende só do professor, da família, ou apenas do aluno, mas de um conjunto de ações formado por todos os envolvidos no processo. Assim, a maneira com que a escola funciona, suas práticas de organização e gestão implicam, diretamente, resultados escolares de seus educandos.

Ao analisar as teorias pedagógicas frente à realidade das escolas públicas e a estratégia de trabalho da equipe gestora, percebe-se, com facilidade, o apreço dos educadores à política da participação, como estratégia de trabalho. Para que esta ação funcione, é preciso criar possibilidades para que a manifestação democrática se consolide em cada educador, educando e agente da comunidade escolar. Por esse motivo, a escola precisa rever o papel do gestor escolar, com vistas a promover a gestão democrática como prática mediadora do trabalho pedagógico.

O objetivo geral desta pesquisa de revisão bibliográfica e caráter qualitativo será estudar as relações existentes entre a prática de gestão democrática e participativa, frente à necessidade da melhoria dos índices de qualidade do ensino público das escolas, analisar as políticas recentes de democratização do ensino, no intuito de construir entendimentos e saberes que ajudem a comunidade escolar a enfrentar os impedimentos impostos à implantação e consolidação da gestão democrática e participativa nas escolas. 


\section{CONCEITUANDO GESTÃO DEMOCRÁTICA E PARTICIPATIVA}

A palavra democracia vem do grego (demos, povo, kratos, poder) e, no seu sentido original, é uma forma de governo na qual o poder de decisão é exercido diretamente pelos cidadãos, segundo o princípio da predominância da maioria (BARSA, 1994). De acordo com Avritzer, (1999. apud BERAS, 2013, p. 22):

A democracia constitui-se um método político, isto é, um certo tipo de arranjo institucional para se alcançar decisões legislativas e administrativas. Desse modo, ela não é capaz de ser um fim em si mesmo, independentemente do tipo de decisão que ela produzirá sob determinadas condições históricas.

Sobre o conceito de gestão, Ferreira (2003, p. 306) afirma que "gestão é administração, é tomada de decisão, é organização, é atingir seus objetivos, cumprir sua função, desempenhar seu papel." O termo gestão veio substituir o termo administração escolar, que, segundo alguns historiadores, sugeria que a unidade escolar era uma empresa. Essa mudança não foi meramente terminológica, trouxe alterações na estrutura gestora das escolas, agora, com o poder de decisão compartilhado e não mais centralizado na figura do administrador.

A gestão democrática torna-se, assim, o ato de administrar, gerir a instituição com vistas a promover a participação de todos os atores envolvidos no processo educacional de forma democrática, buscando a melhoria do ensino. Esse modelo de gestão veio para substituir o modelo tradicional e autoritarista empregado nas escolas por décadas, levando os componentes da comunidade escolar a refletir sobre qual o papel do gestor e a buscar uma escola que seja participativa, alcançando a formação integral do cidadão e um ensino de qualidade.

Ao assumir esse novo conceito, a escola passa a ser sinônimo de espaço autônomo e participativo. Isso implica trabalho coletivo e compartilhado entre todos os componentes da comunidade escolar. Apesar das discussões sobre o assunto e capacitações dos profissionais, ainda não se conseguiu definir o papel de cada indivíduo frente às novas definições e políticas. Para que isso aconteça, é preciso traçar os objetivos a serem alcançados e preparar todas as pessoas envolvidas para que se alcancem tais objetivos.

[...] Considerando que uma sociedade democrática só se desenvolve e se fortalece se contar com a ação consciente e conjunta de seus cidadãos, não deixa de ser paradoxal que se a escola pública, lugar supostamente privilegiado do diálogo e do desenvolvimento crítico das consciências, ainda resista tão fortemente 
a propiciar valores e conhecimentos, capacite e encoraje seus alunos a exercer de maneira ativa sua cidadania na construção de uma sociedade melhor. (PARO, 2007, p. 18).

A construção da gestão democrática implica luta pela garantia da autonomia da unidade escolar, participação efetiva nos processos de tomada de decisão, incluindo a implementação de processos colegiados nas escolas, e ainda, financiamento pelo poder público, entre outros.

A gestão democrática é entendida como participação efetiva dos vários segmentos que compõem a comunidade escolar, pais, professores, estudantes e funcionários da instituição, a fim de construir e avaliar projetos pedagógicos, administrar os recursos da escola e, não apenas isso, participar dos processos decisórios da escola e ter voz neles. Maia e Costa (2013, p. 61) admitem que:

Ao falarmos de participação efetiva, queremos dizer todos, desde as crianças da educação infantil, pais, professores, alunos, funcionários, equipe pedagógica, direção, representantes da comunidade, ex-educandos e ex-educadores, enfim, todos os que compõe a comunidade escolar e se preocupam com ela e com a busca constante de melhoria de seu papel social.

Não basta uma escola para todos apenas no sentido da oferta de vagas. Wittman e Klippel (2012) e Maia e Costa (2013) concordam que a democratização e participação efetiva pressupõem a participação de todos, ou seja, essa escola tem que ser democrática de fato, com uma administração participativa que abarque, em seu processo de tomada de decisão, todos os envolvidos com a comunidade escolar de forma direta ou indireta. Democracia na escola refere-se à utilização de mecanismos na gestão escolar como conselho da escola, associação de pais e mestres, grêmio estudantil e, eventualmente, eleição de dirigentes. (PARO, 2007)

“A participação é um direito e um dever de todos que integram uma sociedade democrática, ou seja, participação e democracia são dois conceitos estreitamente associados” (HORA, 1994, p. 53). A gestão democrática e participativa é de grande importância como recurso de participação humana e de formação para a cidadania e sua necessidade para a construção de uma sociedade mais justa, humana e igualitária é indubitável. 


\section{FUNDAMENTAÇÃO LEGAL}

A gestão escolar é legalmente fundamentada e a legislação pertinente determina que tal gestão seja democrática. A Lei de Diretrizes e Bases da Educação - LDB (Lei $\mathrm{N}^{\circ}$ 9.394/96) faz referência direta à gestão democrática em pelo menos três momentos. O inciso VIII do artigo $3^{\circ}$, o qual define os princípios que norteiam a forma de ministrar o ensino, fixa o da gestão democrática do ensino público.

Conforme estabelecido no artigo $3^{\circ}$, o artigo 14 da LDB também dispõe sobre a gestão democrática do ensino, no qual a democratização da gestão se reduz a um ideal de orientação de atividades de escolas e universidades e ao incentivo à participação da comunidade.

A Resolução da LDB - 9.394, de 1996, em seu Art. 14, estabelece que:

Os sistemas de ensino definirão as normas da gestão democrática do ensino público na educação básica, de acordo com as suas peculiaridades e conforme os seguintes princípios:

I - Participação dos profissionais da educação na elaboração do projeto pedagógico da escola;

II - Participação das comunidades escolar e local em conselhos escolares ou equivalentes.

A mesma Lei prescreve que:

Art. 15. Os sistemas de ensino assegurarão às unidades escolares públicas de educação básica que os integram progressivos graus de autonomia pedagógica e administrativa e de gestão financeira, observadas as normas gerais de direito financeiro público.

No Art. 56, em seu parágrafo único, no capítulo que trata da educação superior, a mesma Lei estabelece que "as instituições de educação superior obedecerão ao princípio da gestão democrática, assegurada a existência de órgãos colegiados deliberativos, de que participarão os segmentos da comunidade institucional, local e regional”.

Ambos os artigos estabelecem a necessidade de desenvolvimento, organização e exercício da gestão democrática da educação, princípio constitucional que é validado no Art. 206 “O ensino será ministrado com base nos seguintes princípios: inciso VI - Gestão democrática do ensino público, na forma desta lei” (BRASIL, 2015. p. 183).

Conquistou-se, na forma da lei, uma gestão democrática dos sistemas de ensino. É necessário compreender que a democracia não é uma opção, e, sim, uma lei que deve ser cumprida. A LDB, assim como a Constituição Federal, regulamentam a gestão democrática 
do ensino público em geral, contribuindo de forma transparente para que as leis sejam aplicadas na educação básica, oferecendo autonomia às unidades federativas para um planejamento adequado às pretensões de cada unidade.

Assim, a gestão democrática é definida com os princípios de integração do sistema, escola com a família, comunidade e sociedade, descentralização e participação no processo educacional, maioria dos professores em colegiados e comissões. Ela supõe a participação da comunidade em suas decisões, participação essa que não deve ficar restrita aos processos administrativos, mas ocorrer nos processos pedagógicos que supõem o envolvimento da comunidade nas questões relacionadas ao ensino.

Porém, o que se vê no Brasil é que a escola pública é vista como propriedade do governo ou do pessoal que nela trabalha, e não como um bem da população. Diretores, professores e funcionários ainda monopolizam os foros de participação, em nome da competência pedagógica. $\mathrm{O}$ diretor escolar tem grandes poderes para dificultar ou facilitar a implantação de procedimentos participativos.

Não se pode mais conceber a escola como arraigada em princípios de autoritarismo, prepotência e antidemocracia, e, sim, como uma visão que deixa de ser utópica, pois é um processo real de cidadania que nos leva a agir de forma compartilhada e participativa na distribuição do poder dentro da instituição de ensino.

\section{A IMPORTÂNCIA DA GESTÃo DEMOCRÁTICA E PARTICIPATIVA PARA UMA EDUCAÇÃO DE QUALIDADE}

Diante das constantes alterações realizadas através das reformas nacionais juntamente com iniciativas no âmbito estadual e municipal, foram formuladas diversas leis e diretrizes que passaram a exigir das escolas um novo posicionamento quanto ao perfil de formação dos educandos. Tais exigências têm influenciado o aprimoramento das práticas pedagógicas e a forma de gestão das instituições de ensino, pressionando-as a repensarem o seu papel na promoção de uma educação de qualidade destinada a todas as classes, gêneros e segmentos sociais. Paro (2007, p. 116) reitera que:

É preciso tornar a unidade escolar um lugar agradável e atrativo a seus usuários diretos e indiretos, dotando-o dos componentes da comunidade externa, na convicção de que sua participação é não apenas um direito de participação no controle democrático do estado nos serviços que este oferece à população, mas também uma necessidade da escola, se esta quer fazer-se de fato educativa. 
Entende-se que educação é uma condição indispensável para que se produza um homem socialmente constituído, formando-o para viver bem em sociedade. A democracia seria, assim, a mediadora dessa construção social. Pelo menos, esse deveria ser o ideal da escola, preparar o educando para agir como cidadão crítico e para exercer democraticamente seus direitos e deveres. Mas preocupam-se mais com avaliações, notas, vestibulares e com a preparação para o mercado de trabalho do que com a construção do saber.

De acordo com Paro (2007), no que diz respeito a sua dimensão social de atuação, a escola vem prendendo-se a um currículo essencialmente informativo, o qual ignora a necessidade de formação ética de seus educandos, como se isso fosse atribuição apenas da família. Mas, sem dúvida alguma, hoje, a principal falha da escola com relação à sua dimensão social parece ser sua omissão na função de educar para a democracia.

A escola parece estar falhando na missão de formar para a cidadania e para a democracia, de modo que, em geral, educadores e autoridades têm produzido, em uma expressiva parte da população, as rudimentares capacidades de ler, escrever e fazer contas.

Para Paro (2007), a verdadeira democracia caracteriza-se pela participação ativa dos cidadãos na vida pública da sociedade na qual está inserido, sendo importante que cada um se considere não apenas como usufruidor dos direitos estabelecidos, mas também como “criadores de novos direitos". Para isso, é preciso que a educação se preocupe em dotar, preparar essas capacidades culturais e intelectuais para essa participação ativa, levando a essa compreensão da educação para a democracia, inserindo-o nas diferentes áreas do conhecimento como parte de sua formação intelectual. "Não adianta gerir democraticamente estruturas antidemocráticas, estruturas excludentes.” (ARROYO, 1996, p. 17).

A busca pela qualidade do ensino e pela democratização da escola pública implica, necessariamente, defender um direito da população. Para tanto, é necessário compreender que democratizar o ensino não consiste apenas em ampliar o número de escolas ou vagas, certamente, ater o foco à quantidade de crianças na unidade escolar é insuficiente. Muito mais que isso, é necessário garantir, além do acesso e da permanência dos alunos na escola, um processo educativo que tenha como cerne o desenvolvimento de habilidades, valores sociais e princípios voltados ao desenvolvimento humano, garantindo sua cidadania e preparação para agir democraticamente. Consoante Hora (1994, p. 20), “[...] a consolidação de uma gestão democrática no interior da escola não é um processo espontâneo e fácil.”

A implementação de um ambiente democrático na escola reveste-se de inúmeros entraves que limitam a efetivação desse processo, como, por exemplo, a ausência 
do esforço coletivo e a falta de definição dos objetivos pedagógicos a serem alcançados. Muitas vezes, a participação ativa da comunidade escolar num todo não ocorre porque as pessoas não sabem como se envolver nos processos. Conforme salienta Paro (2007, p. 28), com relação aos que estão envolvidos com o cotidiano escolar, parece que as políticas educacionais têm passado à margem da opinião de quem o ensino depende inquestionavelmente para ser realizado: os atores da prática educativa escolar, em especial os professores e estudantes.

Hora, (1994, p. 120) afirma ainda que:

A gestão democrática na educação inclui necessariamente, a participação da comunidade no processo educacional, sem o que seria muito mais um arranjo interno dos componentes da escola que atenderiam a interesses que certamente não estariam consentâneos com as expectativas comunitárias.

É necessário que a escola implante nos educandos valores democráticos, que não se aprende apenas de forma intelectual, mas é formado pela consciência ética, por debates, participação nas decisões escolares, direito ao voto, direito de voz e pela formação moral. Wittman e Klippel (2012, p. 21) descreve como "uma educação que propicie autonomia seres capazes de decifrar uma informação e interagir com a situação a partir do convívio democrático."

A mudança adotada por parte das escolas, em todo o Brasil, na forma de escolha do diretor escolar para eleição, é considerada como contribuinte para a democratização da gestão escolar, pois, ao ser eleito pela comunidade escolar, o diretor tem legitimidade em sua função, o que pode levar a comunidade a uma participação mais efetiva. "As eleições diretas para diretores, historicamente, têm sido uma das modalidades tidas como das mais democráticas formas, apesar de se constituírem também uma grande polêmica.” (BRASIL, 2004, p. 38).

O novo modelo não só abre espaço para a inciativa e participação como cobra isso da equipe escolar - alunos e pais. Ele delega poderes à diretoria para resolver os desafios da qualidade na educação no âmbito da instituição, ao passo que sugere engajamento e sintonia com o grupo que está envolvido e que tem muito a ganhar com a superação do desafio.

Para que uma escola precisa funcione a contento, é imprescindível que seja democrática. A ação da gestão democrática e participativa abre canal para a participação da comunidade. Assim, a escola deixa de ser um lugar fechado e separado da realidade e passa a integrar a comunidade educativa, interagindo, substancialmente, com a sociedade civil. 
E o mais importante, a educação para a vivência em sociedade, para pensar, falar e agir democraticamente pode tornar-se efetiva.

Precisamos entender que o ser humano é o único ser vivo que se desenvolve historicamente através de sua participação na criação do mundo e, por esta razão, não pode ser relegado à mera situação de receptor, e, sim, de ator e sujeito. Os valores como a inclusão, justiça, participação e diálogo são próprios da democracia, por isso, é tão importante democratizar o ambiente escolar. Quando agimos democraticamente, a diversidade é valorizada, a inclusão se torna prática e reconhecemos como útil a participação, a decisão e a ideia do outro. É por essas veredas que a preparação dos educandos para assumirem uma postura crítica como ser social podem se concretizar.

\section{CONSIDERAÇÕES FINAIS}

Ao finalizar este artigo, podemos concluir que, embora tenha sido fixada pela Constituição Federal e assegurada pela LDB, ainda não se conseguiu, de fato, implantar, no interior de grande parte escolas, uma gestão democrática do ensino que promova a participação efetiva de toda a comunidade escolar nos processos que envolvem as instituições de ensino.

Infelizmente, na realidade que se apresenta, tem-se observado que, apesar do discurso da gestão democrática em voga no sistema educacional e assegurado pela legislação brasileira, ainda estamos em processo de iniciação de desenvolvimento desse tipo de gestão, entendida como pressuposto da participação coletiva da comunidade escolar.

Este fato tem se mostrado como um grande desafio a ser enfrentado. Muitos entraves como a ausência do esforço coletivo e a falta de definição dos objetivos pedagógicos a serem alcançados têm dificultado o êxito na democratização dos sistemas escolares. Faz-se necessário o esforço coletivo para que se consiga combater os empecilhos impostos à concretização desse modelo de gestão que pressupõe a participação de todos os membros da comunidade escolar, inclusive nas tomadas de decisão quanto aos processos tanto administrativos como pedagógicos - que se relacionam ao ensino e que melhoram a qualidade do ensino. "Assumir essa postura em sua escola significa assumir que a escola e gestão democrática passam a ser duas dimensões indissociáveis e inalienáveis na construção de uma prática educativa de qualidade.” (WITTMAN; KIPPEL, 2012 p. 81).

Por isso, o diretor ou gestor escolar deve atuar como mediador das posturas adotadas no âmbito da unidade escolar, levando a comunidade a agir de forma 
compartilhada e participativa. As relações de poder têm entravado o processo de democratização da gestão escolar, pressionando os gestores a se tornarem opressores com seus dirigidos e subservientes aos dirigentes dos órgãos governamentais centrais aos quais as escolas estão ligadas, e a usarem um pseudodiscurso de gestão democrática e participativa só para garantir a conformidade de sua ação aos padrões legais exigidos. Caso contrário, a escola é abandonada à própria sorte e tem como resultado o enfraquecimento da gestão, da imagem profissional do gestor e da credibilidade da democracia institucionalizada como um todo. Esse é o posicionamento que a gestão democrática e participativa combate.

As alterações realizadas através das reformas nacionais têm exigido um novo posicionamento quanto ao perfil de toda a comunidade escolar, pressionando-os a repensarem seu papel na promoção de uma educação de qualidade. É preciso focar menos no currículo e mais em dotar e preparar o cidadão para a participação ativa.

O novo modelo de gestão não só abre espaço para a iniciativa como cobra isso da equipe escolar - alunos e pais. Ele envolve a comunidade, abre espaço para novas ideias e incentiva o educando a se tornar um ser crítico e pensante.

\section{REFERÊNCIAS}

ARROYO, Miguel G. Administração e qualidade da pratica educativa: exigências e perspectivas. Revista Brasileira de Administração da Educação. Brasília, v. 12, n. 1, jan./jun. 1996.

BARSA, Enciclopédia. Encyclopaedia Britannica Consultoria Editorial LTDA. Encyclopédia Britânica do Brasil. Volume 06. Rio de Janeiro - São Paulo: Publicações LTDA, 1994.

BERAS, Cesar. Democracia, cidadania e sociedade civil. Curitiba: InterSaberes, 2013.

BRASIL. Constituição Federal (1988). Constituição da República Federativa do Brasil. 7. ed. Barueri: Manoele, 2015.

BRASIL. Ministério da Educação. Secretaria de Educação Básica. Programa de Fortalecimento dos Conselhos Escolares. Conselho escolar, gestão democrática da educação e escolha do diretor Brasília: MEC/SEB, 2004. Disponível em: http://portal.mec.gov.br/seb/arquivos/pdf/Consescol/ ce_cad5.pdf. Acesso em: 12 de julho de 2016.

FERREIRA, Naura Syria Carapeto. A gestão da educação e as políticas de formação de profissionais da educação: desafios e compromissos. In: FERREIRA, N.S.C. (org.). Gestão democrática da educação: atuais tendências, novos desafios. São Paulo: Cortez, 2003.

HORA, Dinair Leal da. Gestão democrática na escola: Artes e ofícios da participação coletiva. $17^{\circ}$ ed. Campinas, SP: Papirus, 1994.

LDB - Lei nº 9394/96, de 20 de dezembro de 1996. Estabelece as diretrizes e bases da Educação Nacional. Brasília: Diário Oficial da União, 1996. Disponível em: http://www.planalto.gov.br/ccivil_03/leis/L9394.htm. Acesso em: 11 de julho de 2016.

MAIA, Bejamin Perez; COSTA, Margarete Terezinha de Andrade. Os desafios e as superações na construção coletiva do projeto político-pedagógico. Curitiba: InterSaberes, 2013. 
PARO, Victor Henrique. Gestão escolar, democracia e qualidade do ensino. São Paulo, Ática, 2007.

WITTMAN, Lauro Carlos; KLIPPEL, Sandra Regina. A prática da gestão democrática no ambiente escolar. Curitiba: InterSaberes, 2012. 